\title{
PHB/Bentonite Compounds. Effect of Clay Modification and Thermal Aging on Properties
}

\author{
Tatiara G. Almeida ${ }^{a}$, Anna Raffaela M. Costa ${ }^{a}$, Renate M. R. Wellen ${ }^{b}$, Eduardo L. Canedo ${ }^{a, c}$,
} Laura H. Carvalho ${ }^{a}$

\author{
${ }^{a}$ Universidade Federal de Campina Grande, R. Aprígio Veloso, 882, Universitário, \\ Campina Grande, PB, Brazil \\ ${ }^{b}$ Universidade Federal da Paraíba, Cidade Universitária, Castelo Branco III, João Pessoa, PB, Brazil \\ 'Instituto de Tecnologia de Pernambuco, Av. Prof. Luís Freire, 700, Cidade Universitária, \\ Recife, PE, Brazil
}

Received: August 02, 2016; Revised: April 12, 2017; Accepted: July 12, 2017

\begin{abstract}
Poly(3-hydroxybutyrate) (PHB) was compounded with three different Bentonite clays: natural, purified by ultrasound/sonicated and organically modified with hexadecyltrimethylammonium bromide. PHB/Bentonite masterbatches with $30 \%$ clay were prepared in a laboratory internal mixer and letdown with pure matrix to $1 \%$ and $3 \% \mathrm{w} / \mathrm{w}$ clay. Test samples were injection molded and characterized by x-ray diffraction (XRD), differential scanning calorimetry (DSC), infrared spectroscopy (FTIR) and scanning electron microscopy (SEM). Increase in Bentonite hydrophobic character was evinced by FTIR for organoclays. XRD of composites showed increase in clay interlayer distance and peak broadening, suggesting formation of intercalated nanocomposites. DSC showed increase in crystallinity and crystallization rate for compounds, especially for PHB/organoclay formulations. Thermal aging was conducted by exposing specimens at $115^{\circ} \mathrm{C}$ for up to 120 hours, and mechanical properties were measured according to ASTM standards. Elastic modulus increased and impact strength decreased with time and clay content; clay purification had little effect on the tensile properties. Tensile strength of thermal aged samples showed little variation, except for the organoclay nanocomposites, for which it significantly decreased with exposure time. SEM images displayed a whitened honeycomb structure and detachment of PHB/Bentonite layers which may be connected to cold crystallization and degradation processes taking place during thermal aging.
\end{abstract}

Keywords: PHB, Bentonite, Nanocomposites, Organophilization, Thermal Aging.

\section{Introduction}

Nowadays there is a growing interest in developing bio-based polymers and innovative process technologies that can reduce the dependence on fossil fuel and move to a sustainable materials basis. So far, the most promising nanoscale fillers are layered silicate clays such as montmorillonite. Bio-nanocomposites open an opportunity for new, high performance, light weight green nanocomposite materials to replace conventional non-biodegradable petroleum-based plastic materials..$^{1-4}$

Polyhydroxyalcanoates, made from natural resources by low-impact biotechnological processes, are among the biodegradable polymers being widely investigated as alternative materials. Recent studies focus on PHB, poly(3hydroxy butyrate), a semi-crystalline polyester obtained by bacterial action upon sugars, with properties similar to many synthetic commodity polymers and processed by standard industrial methods. PHB is biocompatible, fully compostable, and quickly degrades under normal landfill conditions to water and carbon dioxide. ${ }^{3,5-7}$

*e-mail: tatiaraalmeida@gmail.com
Bentonite is natural clay whose main component is the mineral montmorillonite; Bentonites are a valuable mineral class for industrial applications because of their high cation exchange capacity and surface area. However, pristine Bentonites contain many impurities, including clay and non-clay minerals as well as organic matter, that may interfere with their cation exchange capacity as well as with nanodispersion of the load in the polymer matrices, in their natural form, Bentonites are hydrophilic, which may render them very difficult to disperse in a hydrophobic polymer matrix. Bentonite purification prior to compounding may somewhat improve the situation, and sonication seems to be a suitable method as it was proven to not only reduce clay particle size but also remove organic matter and some accessory minerals, that may hinder organophilization and expansion from the suspension ${ }^{11}$. Previous works have shown clay organophilization, a procedure where interlayer inorganic cations are replaced by organic quaternary ammonium cations, to increase the clay interlayer distance and diminish its hydrophilic character leading to better dispersed intercalated clay/polymer systems and, in some cases, to exfoliated systems. ${ }^{7-11}$ 
The present work aims to compare the structure and properties of PHB/Bentonite compounds prepared with natural (AN), ultrasound-purified (AP), and purified and organophilized (AO) clay; Bentonite was added to PHB as an effort to improve its performance. The compounds were characterized by infrared spectroscopy (FTIR), X-ray diffraction (XRD), differential scanning calorimetry (DSC) and scanning electronic microscopy (SEM). The work also objectives to investigate the influence of AN, AP and AO with $1 \%$ and $3 \%$ clay levels in the mechanical behavior as well as the impact behavior of PHB compounds performed during a thermal aging study.

\section{Experimental}

\subsection{Materials}

The polymer resin used was poly(3-hydoxybutyrate) (PHB), actually a random copolymer with approximately $4 \%$ of 3-hydoxyvalerate units, supplied by PHB Industrial SA (Brazil). The clay was sodium Bentonite clay Brasgel grade, from Bentonit União Nordeste (Campina Grande, Brazil), with density $2.6 \mathrm{~g} / \mathrm{cm}^{3}$ and $0.92 \mathrm{meq} / \mathrm{g}$ cation exchange capacity. The salt used was hexadecyltrimethylammonium bromide (cetremide) pursached from Vetec.

\subsection{Methods}

\subsubsection{Purification and organophilization of bentonite clay}

The sodium Bentonite "natural" clay (AN), was screened (\#200 mesh screen) and dispersed in water at 2\% w/w with vigorous agitation; it was sonicated with a Crisofolis ultra-sound bath for $30 \mathrm{~min}$, filtered, dried and re-screened (\#200 mesh), to obtain the purified clay (AP).

Purified clay thus obtained was organophilized with hexadecyltrimethylammonium bromide (cetremide) salt using a standard procedure developed in our laboratory and described elsewhere ${ }^{11}$ to obtain the organoclay used in the present work $(\mathrm{AO})$.

\subsubsection{Compounding}

Masterbatches with $30 \%$ clay (natural, purified, purified organoclay) were compounded in a laboratory internal mixer Haake Rheomix 3000 with high intensity rotors, operating at $150^{\circ} \mathrm{C}, 60 \mathrm{rpm}$ for 7 minutes. The concentrates were diluted to final clay concentration of $1 \% \mathrm{w} / \mathrm{w}$ and $3 \% \mathrm{w} / \mathrm{w}$ with neat PHB in a corotating twin-screw extruder Imacon DCR 30:40 operating at $150 \mathrm{rpm}$ and $35 \mathrm{~kg} / \mathrm{h}$, with barrel temperature set at $160^{\circ} \mathrm{C}$.

Test specimens for tensile (ASTM D 638) and impact (ASTM D 256) tests were injection molded in a Romi Pratica $130 \mathrm{~T}$ equipment, with extruder barrel temperature set at $155 / 185^{\circ} \mathrm{C}$ and mold temperature at $35^{\circ} \mathrm{C}$.

\subsubsection{Characterization}

The compounds were characterized by infrared spectroscopy (FTIR) in an Avatar TM 360 Nicolet instrument in the region of 4000-650 $\mathrm{cm}^{-1}$; by X-ray diffraction (XRD) in a Shimadzu XRD-6000 instrument in the region of $2-30^{\circ}(2 \theta)$ and by differential scanning calorimetry (DSC) in a TA Instruments DSC Q-20 using a three-stage temperature program: heating from ambient temperature $\left(25^{\circ} \mathrm{C}\right)$ to $200^{\circ} \mathrm{C}$, cooling to $25^{\circ} \mathrm{C}$ and reheating to $200^{\circ} \mathrm{C}$ under nitrogen atmosphere at a heating/ cooling/reheating rate of $10^{\circ} \mathrm{C} / \mathrm{min}$ with $5 \mathrm{mg}$ samples.

Aging was conducted in an air circulation oven at $115^{\circ} \mathrm{C}$ on tensile and impact specimens and their tensile properties as a function of thermal exposure times of 0, 24, 72 and 120 hours were measured. Mechanical properties were measured according to ASTM standards. Tensile tests were conducted in a Lloyd LR $10 \mathrm{~K}$ universal testing machine operating at 5 $\mathrm{mm} / \mathrm{min}$ rate of elongation, and impact testing was carried out in a CEAST Resil-5.5 impact machine operating with a $2.75 \mathrm{~J}$ pendulum on notched specimens in Izod configuration.

\section{Results and Discussion}

\subsection{Infrared spectroscopy}

Figure 1 shows the FTIR spectra of the natural (AN), purified (AP) and purified organophilic (AO) clays used to prepare $\mathrm{PHB} /$ Bentonite compounds. The spectra of all samples are very similar. The peaks in the 3700-3200 $\mathrm{cm}^{-1}$ region are attributed to vibrations of hydroxyl groups present in Bentonite and to adsorbed/intercalated water. The intensity of these peaks decreased with clay purification and particularly with clay purification and organophilization, indicating that the chemical modification reduced the clay hydrophilic character. The peaks 660, 1450 and 1100-800 $\mathrm{cm}^{-1}$ regions are typical of Bentonite clays and attributed to $\mathrm{Si}-\mathrm{O}-\mathrm{Si}, \mathrm{Si}-\mathrm{OH}$ and Al-O-Si bonds. The organoclay shows weak peaks at 2920 and $2860 \mathrm{~cm}^{-1}$ associated with asymmetric and symmetric axial deformations of $\mathrm{CH}_{3}$ and $\mathrm{CH}_{2}$ groups, respectively, attributed to the ammonium salt used to chemically modify the clay. The organophilization process diminished the clay hydrophilic character, probably improving clay dispersion in PHB matrix, so lower levels of segregation are expected for the system PHB/AO. ${ }^{12-14}$.

\subsubsection{X-Ray diffraction}

X-ray diffratograms of clays and PHB compounds investigated in this work are shown in Figures 2 and 3 and the interlayer basal distance, $d_{001}$ is presented in Table 1 .

From Figure 2 is evidenced that quartz contaminant was nearly completely removed and that clay structure was not changed after ultrasound exposure. Similar results were reported for sonicated clays, and indicated that a decrease in quartz and possibly organic (humic material) clay contaminants took place. ${ }^{11-12}$ 


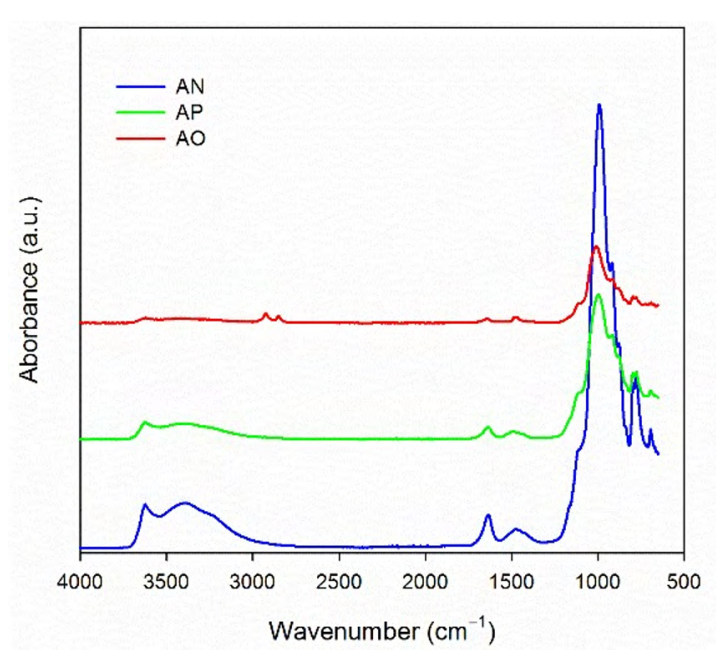

Figure 1. FTIR spectra of natural (AN), purified (AP) and purified/ organophillized (AO) Bentonite clays.

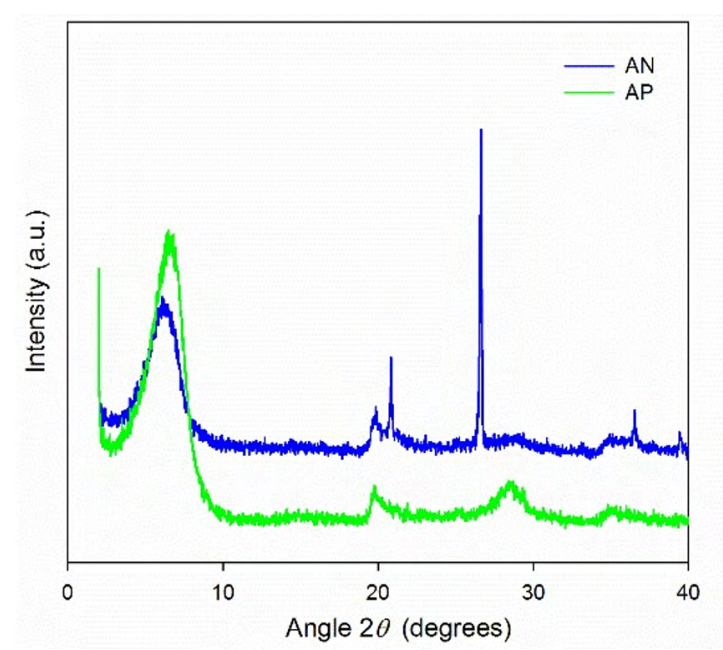

Figure 2. X-Ray diffratograms of natural (AN) and purified (AP) clays over a wider range of $2 \theta$.

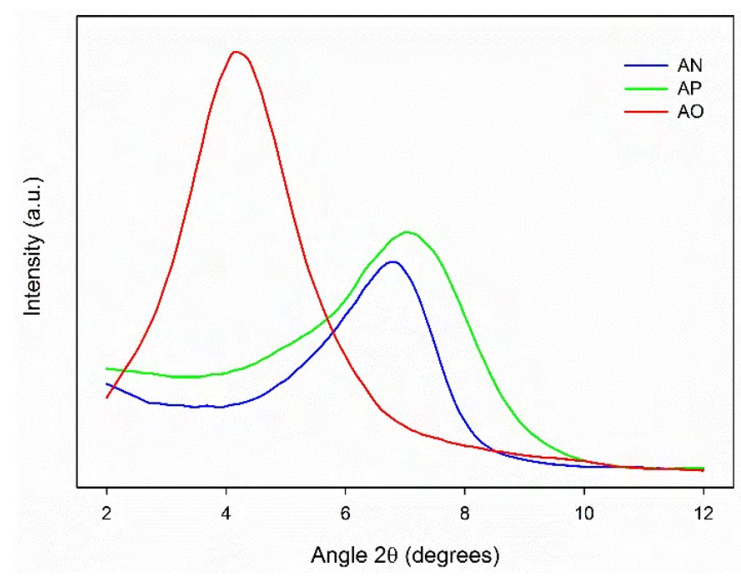

Table 1. Basal distance $d_{001}$ of the Bentonites and PHB compounds

\begin{tabular}{lcc}
\hline Sample & $2 \theta\left(^{\circ}\right)$ & $d_{001}(\mathrm{~nm})$ \\
\hline Natural clay (AN) & 6.9 & 1.28 \\
Purified clay (AP) & 7.2 & 1.23 \\
Purified organoclay (AO) & 4.1 & 2.16 \\
PHB1\%AN & 5.6 & 1.55 \\
PHB1\%AP & 5.4 & 1.50 \\
PHB1\% AO & 4.5 & 1.95 \\
\hline
\end{tabular}

The data in Figure 3 and Table 1 also show that the basal distances of the natural and purified clay were nearly equivalent and that organophilization was successful as the basal distance increased from around $1.2 \mathrm{~nm}$ to $2.16 \mathrm{~nm}$, indicating that the organic cation was incorporated within the clay galleries. The basal spacing of the PHB/clay compounds were higher than those of the natural and purified clays, indicating that PHB chains also penetrated the clay structure. The decrease in the basal distance of the organoclay in the hybrid $(1.95 \mathrm{~nm}$ vs $2.16 \mathrm{~nm}$ for the organoclay alone) indicates partial clay structure collapse which can be attributed to a tendency to form clay agglomerates or to partial degradation of the organic modifier during processing. Similar behavior was observed for this same organoclay incorporated in PET and PE. ${ }^{11-14}$

\subsubsection{Differential scanning calorimetry}

DSC data for PHB and PHB/Bentonite compounds are shown in Figure 4, Tables 2, 3 and 4 for the three stage temperature program described in the experimental section. All DSC data were tabulated and Table 2 defines the parameters whose numerical values are reported in Tables 3 and 4 .

A single melting peak was observed for PHB, PHB/AN, and $\mathrm{PHB} / \mathrm{AP}$ on the first heating stage while a wider double peak was displayed by PHB/AO. On the second melting all systems displayed either a shoulder (PHB/AN and PHB/

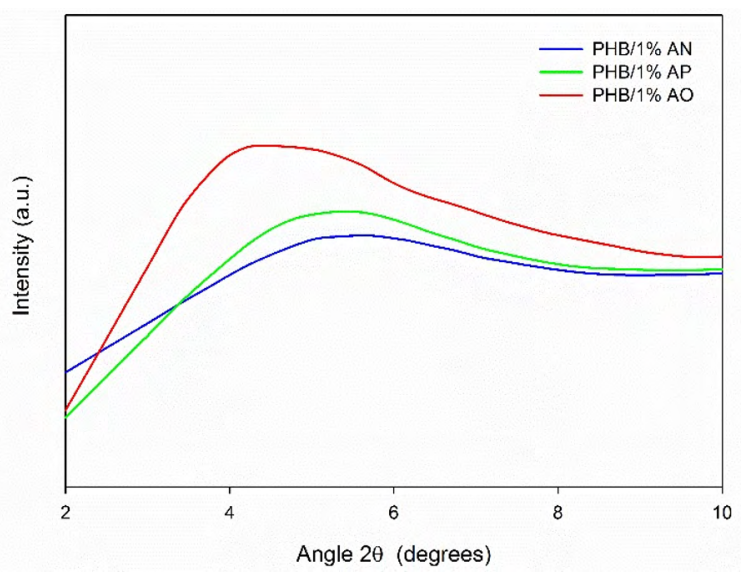

Figure 3. X-Ray difractograms of natural (AN), purified (AP) and purified/organophilic (AO) Bentonite clays (left) and, for PHB compounds with $1 \%$ of these clays (right). 

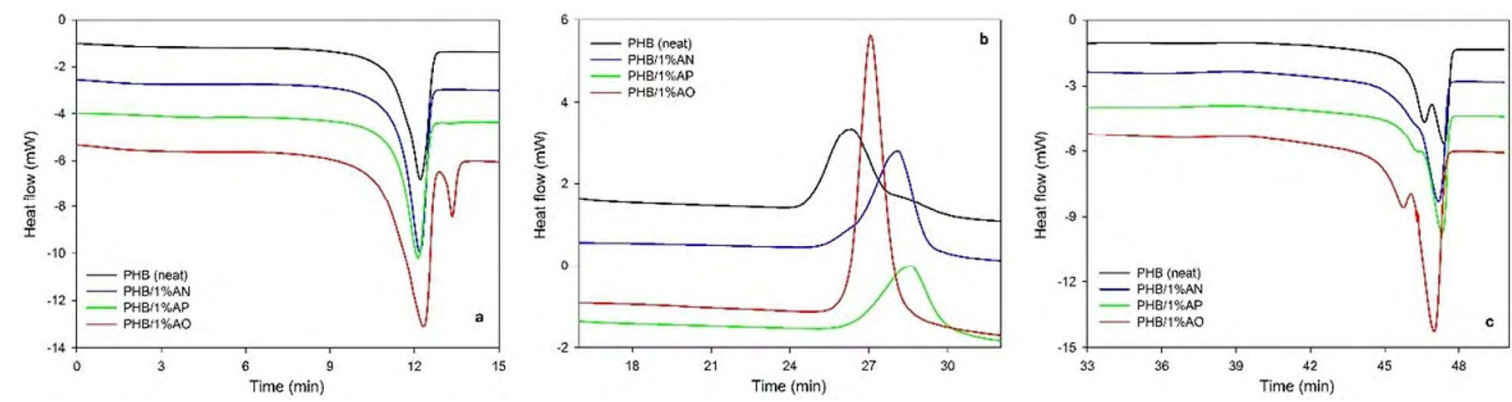

Figure 4. DSC scans for a three stage temperature program of Neat PHB and PHB/Bentonite compounds. a) first heating, b) first cooling and c) second heating.

Table 2. Definition of crystallization/melting parameters reported in Tables 3 and 4

\begin{tabular}{lc}
\hline$\Delta T$ & Crystallization/melting temperature interval (1-99\%) \\
\hline$T_{\mathrm{p}}$ & Peak crystallization/melting temperature \\
$T_{\mathrm{m}}$ & Full (99.9\%) melting temperature \\
$\Delta H$ & Specific heat of crystallization/melting \\
$X_{\mathrm{c}}$ & Mass (absolute) crystallinity \\
$c_{1-99 \%}$ & Average rate of crystallization/melting (1-99\%) \\
$c_{\max }$ & Maximum rate of crystallization/melting (at $\left.T_{\mathrm{p}}\right)$ \\
$\tau_{1 / 2}$ & Half crystallization/melting time $(0-50 \%)$ \\
\hline
\end{tabular}

Table 3. Selected crystallization parameters, PHB and PHB/ Bentonite compounds.

\begin{tabular}{lcccc}
\hline \multirow{2}{*}{ Parameter } & \multirow{2}{*}{ PHB } & \multicolumn{3}{c}{ PHB compounds with $1 \%$} \\
\cline { 3 - 5 } & & AN & AP & AO \\
\hline$\Delta T_{\mathrm{c}}\left({ }^{\circ} \mathrm{C}\right)$ & $105-54$ & $98-53$ & $93-41$ & $93-61$ \\
$T_{\mathrm{p}}\left({ }^{\circ} \mathrm{C}\right)$ & 87.4 & 69.8 & 64.8 & 80.7 \\
$\Delta H_{\mathrm{c}}(\mathrm{J} / \mathrm{g})$ & 51.2 & 55.8 & 43.8 & 85.0 \\
$X_{\mathrm{c}}(\%)$ & 35.0 & 38.2 & 30.0 & 58.3 \\
$c_{1-99 \%}\left(\mathrm{~min}^{-1}\right)$ & 0.195 & 0.221 & 0.188 & 0.310 \\
$c_{\max }\left(\mathrm{min}^{-1}\right)$ & 0.446 & 0.510 & 0.441 & 0.881 \\
$\tau_{1 / 2}(\min )$ & 2.2 & 3.2 & 3.4 & 1.8 \\
\hline
\end{tabular}

Table 4. Selected melting parameters of the second melting stage of PHB and PHB/Bentonite compounds.

\begin{tabular}{lcccc}
\hline \multirow{2}{*}{ Parameter } & \multirow{2}{*}{ PHB } & \multicolumn{3}{c}{ PHB compounds with $1 \%$} \\
\cline { 3 - 5 } & & AN & AP & AO \\
\hline$\Delta T_{\mathrm{m}}\left({ }^{\circ} \mathrm{C}\right)$ & $132-176$ & $140-174$ & $141-175$ & $141-173$ \\
$T_{\mathrm{p}}\left({ }^{\circ} \mathrm{C}\right)$ & 172.8 & 175.3 & 171.9 & 168.5 \\
$T_{\mathrm{m}}\left({ }^{\circ} \mathrm{C}\right)$ & 176.8 & 175.3 & 176.1 & 175.0 \\
$\Delta H_{\mathrm{m}}(\mathrm{J} / \mathrm{g})$ & 66.4 & 73.8 & 62.4 & 103.9 \\
$X_{\mathrm{c}}(\%)$ & 45.5 & 50.6 & 42.8 & 71.2 \\
$c_{1-99 \%}\left(\mathrm{~min}^{-1}\right)$ & 0.225 & 0.291 & 0.293 & 0.305 \\
$c_{\max }\left(\mathrm{min}^{-1}\right)$ & 0.739 & 0.853 & 0.992 & 0.860 \\
$\tau_{1 / 2}\left(\mathrm{~min}^{2}\right)$ & 176 & 174 & 175 & 173 \\
\hline
\end{tabular}

AP) or a double peak (PHB and PHB/AO). Melting double peaks may be associated with crystals having different thermal stabilities, crystal perfection or crystallite sizes, polymorphism, and re-crystallization taking place during fusion. ${ }^{15-21}$

Regarding the melt crystallization, a single peak was observed for all systems and that of $\mathrm{PHB} / \mathrm{AO}$ compound was narrower and more intense, suggesting a more uniform crystallite size. It is believed that this evidence may be linked to the ammonium cations leading to PHB degradation, breaking the macromolecules and, contributing to a higher degree of crystallinity. ${ }^{4,13}$

These curves are better analyzed by observing the melting and crystallization rates of $\mathrm{PHB}$ and, $\mathrm{PHB}$ /clays as shown in Figure 5 and Table 4. The data indicate that the second melting temperatures and rates for all systems under investigation are similar and fairly independent of clay addition or modification. The melt crystallization behavior, though, is different. The crystallization rate for $\mathrm{PHB}$ is a little lower than those of $\mathrm{PHB} /$ clay compounds; fairly independent of clay purification and higher for the system with purified organoclay. Reports from literature state that Bentonite clays may nucleate or slow down polymer crystallization. Results obtained in the present work suggest that the purified organoclay is well dispersed in PHB matrix and that this ordered arrangement leads to narrower peak and faster crystallization rates. The data also show that the degree of crystallinity of the PHB/ AO system was higher than any of the other compounds investigated here (Table 3)..$^{22-23}$

\subsubsection{Thermal aging and mechanical properties}

Tensile properties for $\mathrm{PHB}$ and $\mathrm{PHB} /$ Bentonite compounds are shown in Figures 6 and 7; impact results are plotted in Figure 8; tables with all obtained data are in Supplementary Information. Thermal aging data indicate that although the modulus tends to increase and elongation at break to decrease with clay content, both these properties were relatively insensitive to clay purification. Slightly higher modulus and elongation at break were exhibited by PHB/AN compounds. 

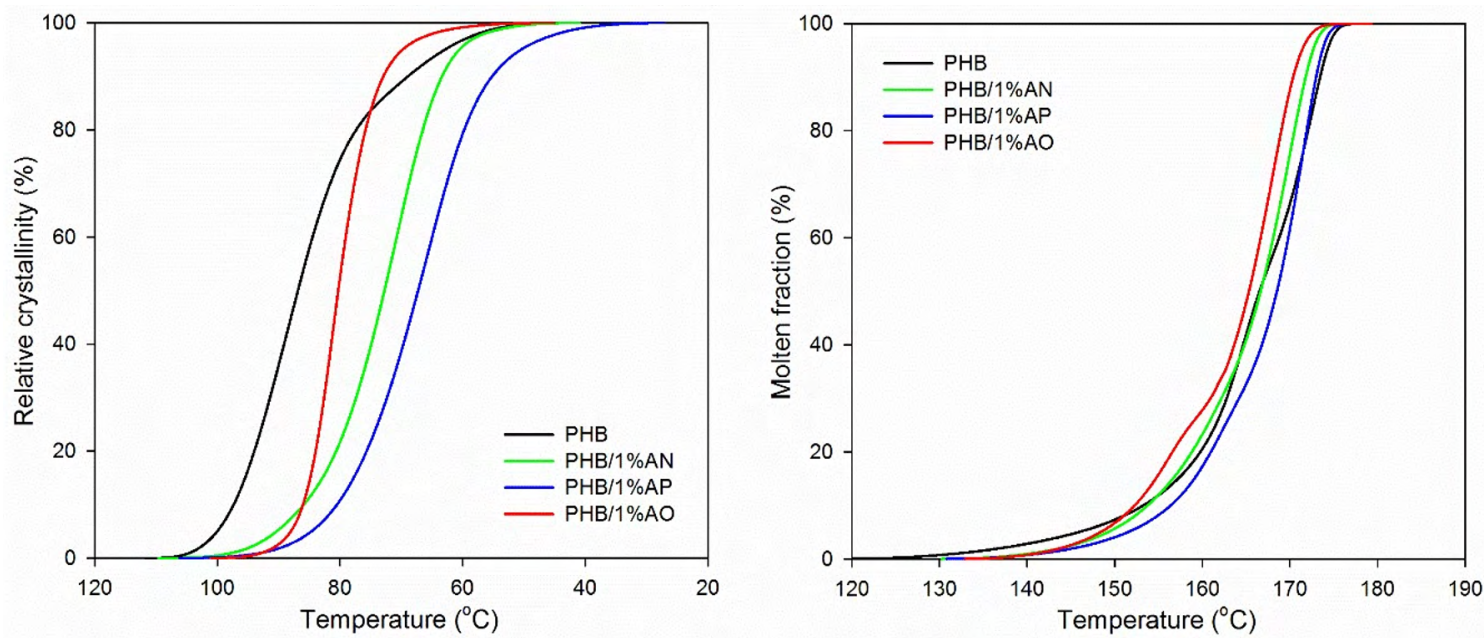

Figure 5. Relative crystallinity (left) and molten fraction (right) as a function of temperature for PHB and PHB/Bentonite compounds.

This behavior was expected and is associated with the higher modulus displayed by the Bentonites and possibly to better clay dispersion and/or clay/polymer adhesion for the compound containing the purified organoclay.

The influence of clay purification on tensile and impact strengths was minimal. However, clay organophilization significantly reduced the impact strength of the systems investigated, indicating that $\mathrm{PHB} / \mathrm{AO}$ systems could not dissipate energy as well as the compounds prepared with natural or purified clays; similar results may be seen for toughness where a significant decrease is observed for the organoclay systems. Since the elongation at break

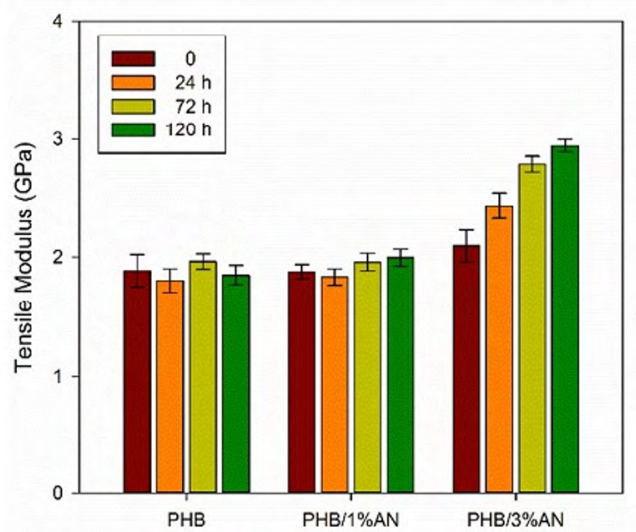

(a)

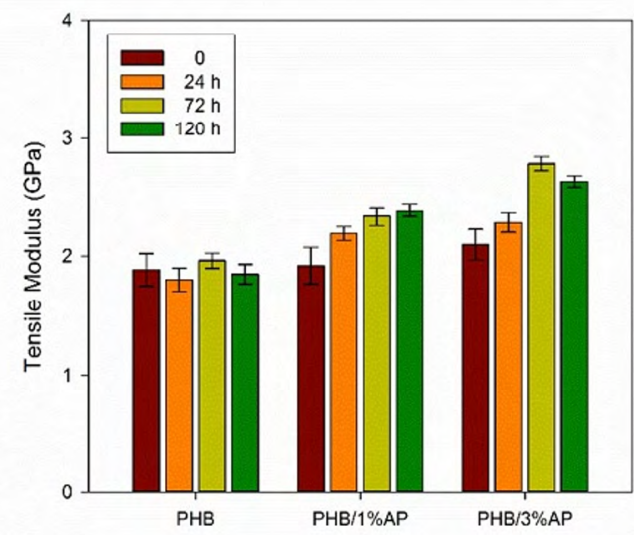

(b)

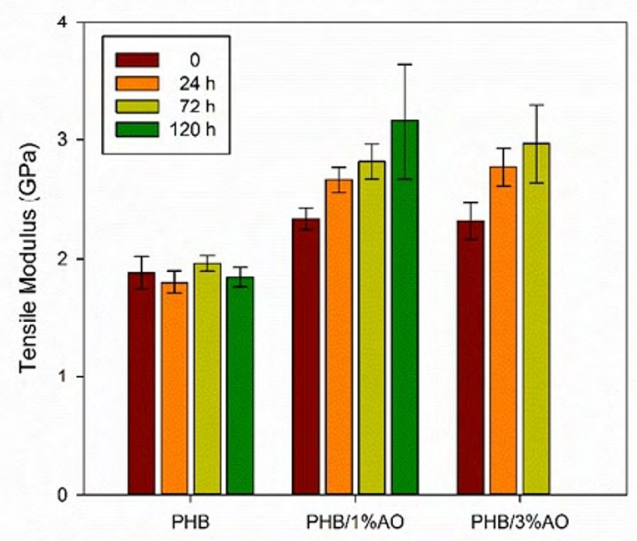

(c)

Figure 6. Effect of thermal aging at $115^{\circ} \mathrm{C}$ for indicated times on the tensile modulus of PHB and PHB compounds with natural (a), purified (b) and, purified/organophilized Bentonite (c). 


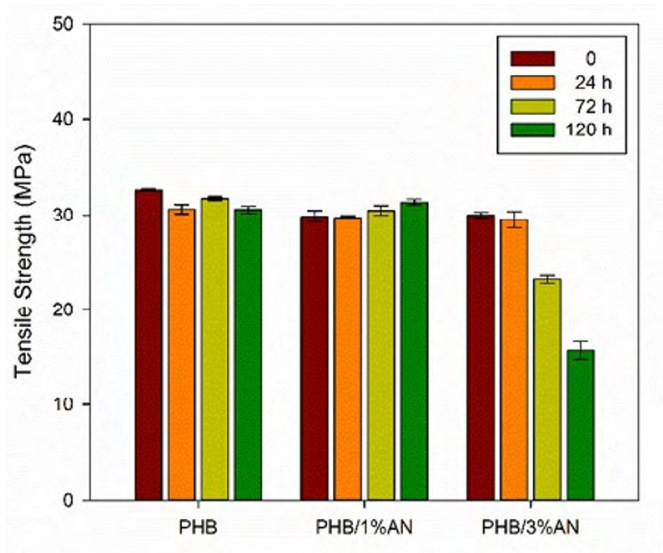

(a)

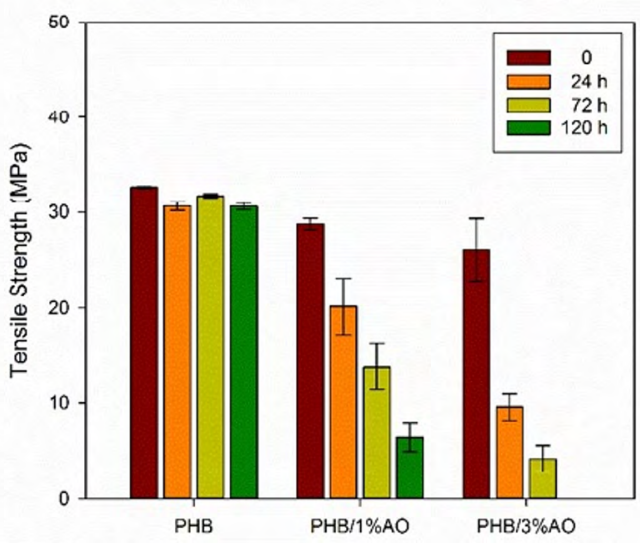

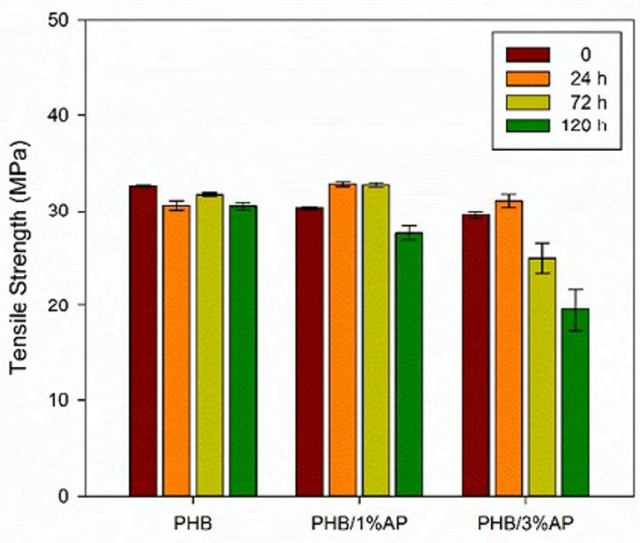

(b)

Figure 7. Effect of thermal aging at $115^{\circ} \mathrm{C}$ for indicated times on the tensile strength of PHB and PHB compounds with natural (a), purified (b) and, purified/organophilized Bentonite (c).

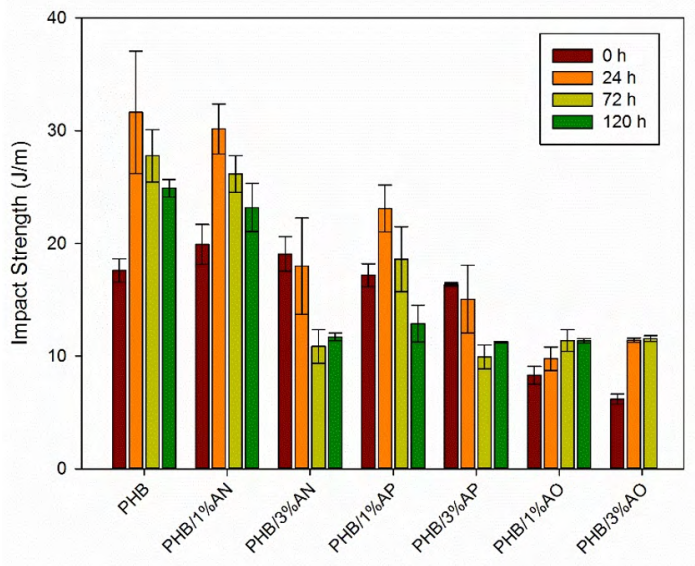

Figure 8. Effect of thermal aging at $115^{\circ} \mathrm{C}$ for indicated times on the impact strength of PHB and PHB compounds with natural, purified and, purified/organophilized Bentonite.

of PHB/AO systems was smaller than those of the other compounds the results seem to indicate that better clay/ polymer adhesion was obtained with the nonorganophilic filled systems. Results observed in the present contribution for the organoclay compounds are similar to those obtained by Romo-Uribe et $\mathrm{al}^{24}$ where the organophilization also did not contribute for the improvement of layered silicate/ acrylate nanocomposites properties.
Regarding the effect of thermal aging at $115^{\circ} \mathrm{C}$ for up to $120 \mathrm{~h}$ on the tensile properties and impact strength of PHB and PHB/Bentonite compounds, the data indicate that, within experimental error, except for the increase in elongation at break, the modulus and tensile strength of the matrix were nearly unaffected by thermal exposure for the time and temperature adopted. Since elongation at break did clearly change, this is taken as an indication that the matrix is being affected by thermal exposure. Since tensile modulus and tensile strength were little affected, it is believed that structural changes do occur (higher crystallization $v s$ chain scission).

The tensile properties of PHB/Bentonite compounds, although displaying similar behavior compared with respect to the matrix, were slightly affected by thermal exposure. The PHB/clay systems increase in modulus and decrease in tensile strength and elongation at break with increasing thermal exposure times. These changes were more significant with higher clay contents and longer exposure times, particularly with the systems compounded with the organoclay. In the latter, the properties of the compounds exposed for $120 \mathrm{~h}$ could not be determined as the samples became too fragile and would rupture during handling.

These observations were taken as an indication that clay organophilization leads to decreased thermal stability of PHB 

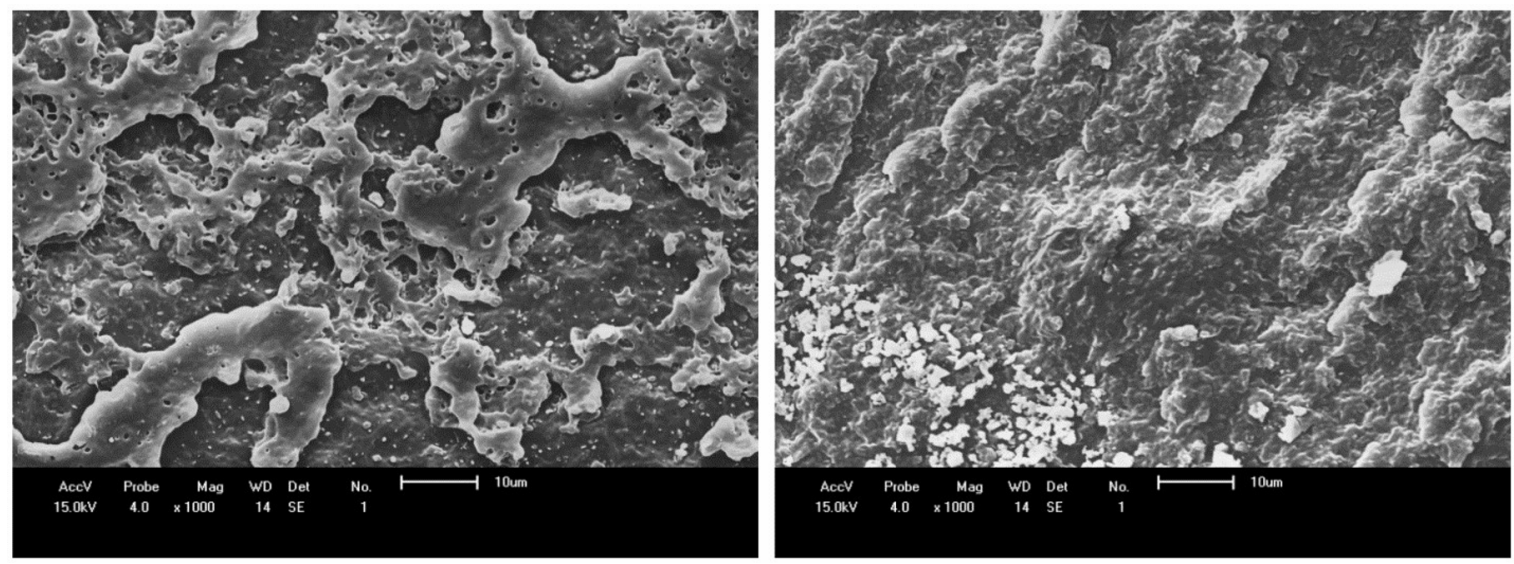

Figure 9. SEM images of fractured surfaces of $\mathrm{PHB} / 1 \% \mathrm{AO}$ before (left) and after (right) thermal aging at $115^{\circ} \mathrm{C}$ for 120 hours Magnification of $1000 x$
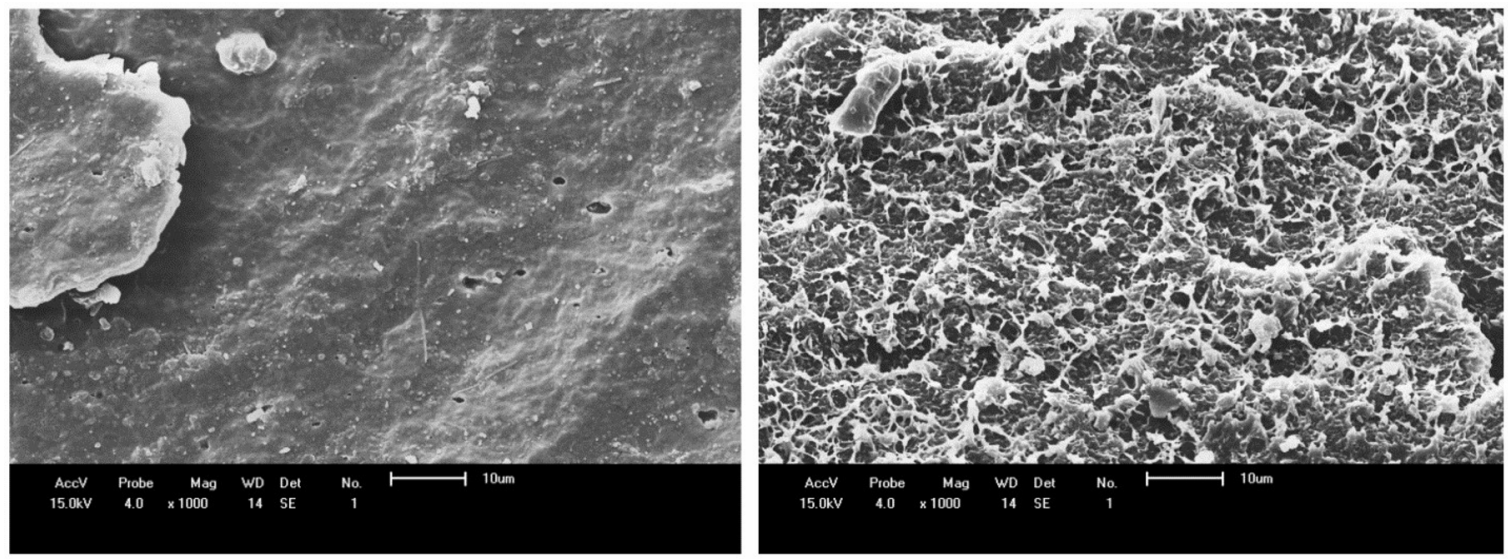

Figure 10. SEM images of fractured surfaces of $\mathrm{PHB} / 1 \% \mathrm{AP}$ before (left) and after (right) thermal aging at $115^{\circ} \mathrm{C}$ for 120 hours. Magnification of $1000 x$

compounds. It is believed that the organic cation is partially degraded during processing, leading to the formation of free radicals which, in turn, may attack the polymer backbone, decreasing its molecular weight. If matrix degradation is not excessive, initially an increase in polymer crystallinity can take place, as shown in Tables 3 and 4 for materials not thermally aged. It is believed that after thermal aging a decrease in thermal stability and molecular weight reduction may have contributed for the lower mechanical properties and also conducted to the detachment of PHB/AO layers as shown in SEM images in Figure 9.

\subsubsection{Scanning electron microscopy}

Figures 9 and 10 present SEM images for $\mathrm{PHB} / 1 \% \mathrm{AO}$ and $\mathrm{PHB} / 1 \% \mathrm{AP}$ compounds, respectively, acquired before and after thermal aging at $115^{\circ} \mathrm{C}$ for 120 hours. Before aging (Figure 10) Bentonite agglomerates, pores and fragile fracture are observed; after thermal aging a whitened honeycomb structure is observed which may be originated from a more crystalline structure developed under propitious conditions for the cold crystallization phenomenon and degradation may also have taken place. In Figure 10, before thermal aging, Bentonite particles appear well dispersed in PHB matrix; after thermal aging detachment of PHB/Bentonite layers is notorious and may have resulted from degradation due lower thermal stability and must have contributed to the lowest values of mechanical properties observed in Figures 7,8 and $10 .{ }^{13-14}$.

\section{Conclusions}

FTIR and XRD data show that Bentonite organophilization was successful as shown by a $68 \%$ increase in clay basal $\left(d_{001}\right)$ distance. DSC data indicated that while PHB/clay compound crystallization was fairly independent of clay purification; clay organophilization led to higher crystallization rates and higher degree of crystallinity for the PHB/Bentonite compounds. The nature and concentration of Bentonite clay affect the physical properties during thermal aging; the compounds become more rigid and weaker with aging, especially the ones containing organoclay, which presented the lowest performance as Bentonite organoclay could not improve 
properly the mechanical properties of PHB compounds, whitened honeycomb structure and detachment of PHB/ Bentonite layers are phenomena observed after thermal aging for $\mathrm{PHB} / \mathrm{AP}$ and $\mathrm{PHB} / \mathrm{AO}$ systems what promoted tensile behavior falling down.

\section{Acknowledgements}

The authors thank Bentonit União Nordeste and PHB Industrial for supplying clay and polymer, respectively, and $\mathrm{CNPq}$ and FACEPE for the financial support.

\section{References}

1. Bucci DZ, Tavares LBB, Sell I. PHB packaging for the storage of food products. Polymer Testing. 2005;24(5):564-571.

2. Reddy CSK, Ghai R, Rashmi, Kalia VC. Polyhydroxyalkanoates: an overview. Bioresource Technology. 2003;87(2):137-146.

3. Falcone DMB, Agnelli JAM, Faria LIL. Panorama setorial e perspectivas na área de polímeros biodegradáveis. Polímeros. 2007;17(1):5-9.

4. Rhim JW, Park HM, Ha CS. Bio-nanocomposites for food packaging applications. Progress in Polymer Science. 2013;38(1011):1629-1652.

5. Bucci DZ, Tavares LBB, Sell I. Biodegradation and physical evaluation of PHB packaging. Polymer Testing. 2007;26(7):908-915.

6. Harding KG, Dennis JS, von Blottnitz H, Harrison STL. Environmental analysis of plastic production processes: Comparing petroleum-based polypropylene and polyethylene with biologically-based poly-ß-hydroxybutyric acid using life cycle analysis. Journal of Biotechnology. 2007;130(1):57-66.

7. Paul DR, Robeson LM. Polymer nanotechnology: Nanocomposites. Polymer. 2008;49(15):3187-3204.

8. Bhattacharya SN, Kamal MR, Gupta RK. Polymer Nanocomposites - Theory and Practice. Munich: Carl Hanser; 2007.

9. Utracki LA, Broughton B, González-Rojano N, Carvalho LH, Achete CA. Clays for polymeric nanocomposites. Polymer Engineering \& Science. 2011;51(3):559-572.

10. Almeida TG. Preparação e propriedades de compósitos de poli(3-hidroxibutirato) e argila: efeito da modificação e teor de carga. [Dissertation]. Campina Grande: Federal University of Campina Grande; 2015

11. Silva SML, Araújo PER, Ferreira KM, Canedo EL, Carvalho LH, Raposo CMO. Effect of clay/water ratio during bentonite clay organophilization on the characteristics of the organobentonites and its polypropylene nanocomposites. Polymer Engineering \& Science. 2009;49(9):1696-1702.

12. Silva EM, Coutinho MGF, Costa RB, Carvalho LH, Canedo EL. Effect of loading level and clay purification on the structure and water vapor permeability of LLDPE/bentonite nanocomposites. Polímeros. 2013;23(1):108-114.

13. Ray SS, Okamoto M. Polymer/layered silicate nanocomposites: a review from preparation to processing. Progress in Polymer Science. 2003;28(11):1539-1641

14. Bikiaris D. Can nanoparticles really enhance thermal stability of polymers? Part II: An overview on thermal decomposition of polycondensation polymers. Thermochimica Acta. 2011;523(12):25-45.

15. Chen X, Hou G, Chen Y, Yang K, Dong Y, Zhou H. Effect of molecular weight on crystallization, melting behavior and morphology of poly(trimethylene terephalate). Polymer Testing. 2007;26(2):144-153.

16. Papageorgiou GZ, Panayiotou C. Crystallization and melting of biodegradable poly(propylene suberate). Thermochimica Acta. 2011;523(1-2):187-199.

17. Furushima Y, Nakada M, Takahashi H, Ishikiriyama K. Study of melting and crystallization behavior of polyacrylonitrile using ultrafast differential scanning calorimetry. Polymer. 2014;55(13):3075-3081.

18. Owen AJ, Heinzel J, Škrbić Ž, Divjaković V. Crystallization and melting behaviour of PHB and PHB/HV copolymer. Polymer. 1992;33(7):1563-1567.

19. Gunaratne LMWK, Shanks RA. Multiple melting behaviour of poly(3-hydroxybutyrate-co-hydroxyvalerate) using step-scan DSC. European Polymer Journal. 2005;41(12):2980-2988.

20. Toda A, Tomita C, Hikosaka M, Saruyama Y. Melting of polymer crystals observed by temperature modulated d.s.c. and its kinetic modelling. Polymer. 1998;39(21):5093-5104.

21. Wellen RMR, Canedo EL, Rabello MS. Melting and crystallization of poly(3-hydroxybutyrate)/carbon black compounds. Effect of heating and cooling cycles on phase transition. Journal of Materials Research. 2015;30(21):3211-3226.

22. D'Amico DA, Manfredi LB, Cyras VP. Crystallization behavior of poly(3-hydroxybutyrate) nanocomposites based on modified clays: Effect of organic modifiers. Thermochimica Acta. 2012;544:47-53

23. Fornes TD, Paul DR. Crystallization behavior of nylon 6 nanocomposites. Polymer. 2003;44(14):3945-3961.

24. Romo-Uribe A, Santiago-Santiago K, Zavala-Padilla G, ReyesMayer A, Calixto-Rodrigues M, Arcos-Casarrubias JA, et al. Waterborne layered silicate/acrylate nanocomposites by in-situ emulsion polymerization: Thermal and mechanical reinforcement. Progress in Organic Coatings. 2016;101:59-70.

\section{Supplementary material}

The following online material is available for this article: Supplementary Information. 